\title{
Countermeasures for Higher Engineering Education Reform under the Idea of Large-Scale Engineering
}

\author{
Liangtao Yang \\ Engineering \& Training Center, Shanghai Second Polytechnic University, Shanghai, China \\ Email: Ityang@sspu.edu.cn
}

Received December 2014

\begin{abstract}
The idea of large-scale engineering provides a new perspective and direction for the reform of higher engineering education. The article has analyzed the connotation of the idea of large-scale engineering education and the challenges of higher engineering education. On this basis, this paper pertinently puts forward some countermeasures to strengthen the higher engineering education reform: clearing the target of engineering education, strengthening engineering practice and humanistic quality education, innovating the personnel training mode, and enhancing the ability of teaching staff.
\end{abstract}

\section{Keywords}

Idea of Large-Scale Engineering, Higher Engineering Education, Reform, Countermeasures

\section{Introduction}

The higher engineering education is an important part of higher education. At present, the scale of China's higher engineering education has reached about $1 / 3$ of the total scale of higher education, the training scale ranks first in the world. Although our engineering education scale is considerable, our engineering innovation and the quality of talent training are still far behind the world level, which restricts the largely industrial enterprises in China and the production efficiency and innovation level, further ascension also has restricted our country comprehensive national strength [1]. It is difficult subject in front of our higher engineering education on how to adapt to the new situation for higher engineering education. At present, how to promote the development of higher engineering education, how to train engineering talents with high quality, has become an important task of the higher engineering education. The idea of large-scale engineering provides a new perspective and direction for the reform of higher engineering education.

\section{The Connotation of the Large-Scale Engineering Education}

The idea of large-scale engineering education is first initiated by the American engineering education. Because the engineering education too much emphasis on professional education and technical education, and at the 
same time the engineering theory is separated from engineering practice, Joel Moses, Dean of the Massachusetts Institute of Technology Institute, strongly appeal that the reform of engineering education should make the engineering education based on the subject, and pay more attention to system and integrity for practical engineering and engineering education. He pointed out that engineering education should not view in narrow perspective which limited in science and technology, must set up the idea of large-scale engineering education based on science and technology, which include society, economy, environment, culture and moral comprehensive. The idea of large-scale engineering provides a new thinking direction for Engineering Education: engineering education is not only the engineering knowledge itself, but also includes comprehensive knowledge of natural science and social science and knowledge of humanities [2]. It emphasizes the important role of engineering practice in talents cultivation. Today, the idea of large-scale engineering should play important leading role to reform and develop engineering education.

The so-called the idea of large-scale engineering does not mean the project scale is very huge, but mean large and complicated engineering require wide and complex scientific knowledge which require cross and amalgamation of political, economic, cultural, ecological and environmental knowledge. The development and construction of modern engineering often have specific goals of economic development or definite social service objective. A large engineering is integration of information and knowledge, which involves not only the knowledge of mathematics, physics knowledge, knowledge in machinery, automation technology and complex engineering principle, also include the factor of culture radiation, economic development, environmental protection and sustainable social development, property with the industry economy. In engineering practice, the engineering personnel should not only use the engineering technology, engineering method and standard enterprise management and other professional knowledge to carry out the project activities, but also pay attention to the engineering value judgment, perception of social problems, to achieve economic and environmental benefits, immediate interests and long-term interests. Therefore, the idea of large-scale engineering essentially is the comprehensive use of rational thinking, comprehensive elements throughout and engineering related, such as the science principle, technical means, economic benefits, social effect and ecological environment and aesthetic orientation. Compared with the traditional view of engineering, modern large-scale engineering education has three characteristics:

The first is comprehensive. The idea of large-scale engineering integrates science, technology and non-technology factors to form a complete system of engineering activities, pay attention to the engineering technology, and at the same time, it integrates non-technology factors into engineering activities.

The second are multiple values. The idea of large-scale engineering breaks out the limit of value philosophy and does not take the pursuit of economic interests as its aim. It puts the economic, social, humanistic, aesthetic and moral values together to realize pluralistic values.

The third is the systematic. The idea of large-scale engineering emphasizes the overall structure of knowledge system, strong ability of engineering practice and application, positive spirit of invention, good quality and humanistic quality. The idea of large-scale engineering corrects the past the drawbacks of engineering technology education such as ignoring the cultivation of humanistic spirit, neglecting creative ability of students and innovative design ability. It has established a moral education first, emphasis on ability, conception of cultivating talents with all-round development, which pointed out the direction for the reform of the engineering education in engineering colleges.

\section{The Current Challenges}

The Eighteenth National Congress of the CPC put forward a comprehensive goal of building a moderately prosperous society. We must adhere to the concept of scientific development to guide the overall economic and social development, speed up the adjustment of economic structure, change the mode of economic growth, improve the capability of independent innovation, take a new road of industrialization Chinese characteristics and build an innovative country. In order to realize the grand strategy, the first problem is to train a large number of senior engineering and technical personnel talents who adapt to the construction of new industrialization China features, which is reliable foundation and fundamental guarantee to take a new road to industrialization [3]. To achieve new goals and new mission, our higher engineering education is facing the following challenges:

The first challenge is to face the engineering practice. At present, there are many problems in our talents cultivation such as no engineering practice exercise enough, the lack of understanding of the important status and 
role in the construction and engineering design in engineering education, the lack of modern engineering design thought, method and the comprehensive use of various aspects of the knowledge and ability to solve practical engineering problems, the lack of the management of modern engineering. More serious is that our Faculty generally lack engineering practice and has only little teachers who have a background in engineering.

The second challenge is close cooperation with the industry and enterprises. Cultivation mode of Chinese engineering education is unitary and relatively closed. It is lack of the participation of industry and enterprise and its adaptability and flexibility is poor, which can't meet the needs of economic and social development of Engineering personnel. The enterprises and universities lack basic interactive mechanism in cultivating high-level engineering and technical personnel.

The third challenge is structural system of engineering education and talent cultivation level. From the discipline and specialty structure, majoring in traditional engineering education to machinery, motor, civil engineering, chemical as the representative of the training scale, all kinds of engineering education has always been in the forefront of the development of national priorities, and the reasonable discipline such as energy, information, material, environment industry professional structure has not yet formed a new cross subject specialty setting. Insufficient coordination between the training requirements of engineering education, educational system and multi-level education, training objectives multi-level education is not clear.

The fourth challenge is that engineering education are facing global industrial structure adjustment and the development of science and technology. With the economic globalization and integration of the regional structure and speeding up the adjustment of the global economy, the world industry structure are facing reshuffle. High information, high tech and high service dominated the new adjustment of industrial structure. Overall, with the parallel transfer of international industrial structure and upgrading of industry, the second industry is showing a trend of development from developed countries to the developing countries. Information and technological innovation is the fundamental driving force of global industrial structure adjustment. With the development of information technology, engineering education should put forward high requirements which are the urgent requirement of Higher Engineering Education in discipline and major adjustment, the construction of curriculum system, renewing teaching contents, training model reform has made rapid response.

\section{The Countermeasures for Higher Engineering Education Reform}

Facing with new goals, new requirement and new task, higher engineering education must clear their responsibility and mission and see the big background and the big trend of development to adapt the adjustment and transformation. This requires the higher engineering education must carry on the new change, enhance their awareness of innovation, clear objectives of the reform and execute the reform measures [4]. The reform should be implemented from the four aspects such as the concept, system, policy and specific measures.

\subsection{Clearing the Target of Engineering Education}

According to our education policy, the objectives of training talent is "cultivating all-round development of socialist successors”, which is the macro requirement of talent quality. According to the needs of society development and enterprises, contemporary engineering education should cultivate innovative engineering talent to adapt to the new characteristics and the new trend of contemporary engineering training. In 2008, we promulgated "the standards of engineering education professional certification", which requires that students must meet 8 basic requirements, mainly in four aspects: deep engineering quality; comprehensive knowledge background; good humanistic quality and social skills. Therefore, the objectives of engineering personnel training can be set as following: cultivating composite and innovative engineering talents who not only has a solid professional skills, but also a broad knowledge base and perfect way of thinking, not only understand the rich knowledge of natural science, but also has the higher the humanities accomplishment.

The training goal of engineering education is a multi-level system which must pay more attention to the all-round development of students. First, it requires a broad knowledge which includes the necessary professional knowledge, the related knowledge of natural science and social science knowledge. The knowledge can help student to solve various problems encountered in engineering practice. Second, it requires the rigorous and open way of thinking. Open thinking refers to the knowledge integration, with different perspective to observe and solve problems; rigorous thinking, refers to the use of strict logical thinking, in-depth thinking on the feasibility of the project. Third, it requires a good quality of personality. Engineering talents must have the humanis- 
tic concern consciousness, a strong desire to benefit human, and in this concept of good exchange and cooperation. The foundation of knowledge, mode of thinking and moral character is the 3D mode of engineering talent. They mutual influence and promote each other and make the college students to obtain a comprehensive and coordinated development of knowledge, ability and personality.

\subsection{Strengthening Engineering Practice}

The most important part of engineering education is the practice teaching and the real connotation of practice teaching is to cultivate students' comprehensive practice ability, research ability and creative ability. The engineering practice can fully arouse the students' consciousness of engineering innovation, stimulate their interest, and cultivate the science spirit and engineering practice ability. Engineering colleges should be based on modern engineering practice, follow the law of talent training, establish perfect practical teaching system of practice teaching, guarantee the implementation, scientific management, strict supervision and reasonable evaluation to realize the function of engineering education. To strengthen the students' engineering practice ability, we should implement from two aspects: one is to pay attention to the practice teaching innovation, pay attention to the mutual coordination between theory course and practice course, pay attention to the gradual basic practice course, comprehensive practice course and innovation practice course. Two is to strengthen the links control of practical teaching, make full use of the understanding of learning, curriculum design, experiment, production practice and graduation design and engineering practice to strengthen the training and guidance of students' practical engineering operation ability, strengthen students' consciousness of engineering, engineering philosophy and way of thinking training of students.

\subsection{Strengthening Humanistic Quality Education}

The idea of large-scale engineering is to develop a comprehensive view of engineering talents, which is to train compound talents in knowledge, ability and personality. Personality is the indispensable humanity quality for engineering talents in engineering practice. Engineering talents should have broad interests, a strong curiosity and thirst for knowledge to incorporate the new idea in engineering design, and maintain a positive and assertive good state of mind. The higher engineering education should be based on the cultivation of humanistic spirit, adhere to the principles of scientific education and humanistic education and require the reasonable curriculum system, a good human environment, highly qualified teaching staff and efficient management mode to effectively implement of humanistic quality education. The first is to establish the humanistic quality education goal. The second is to establish the curriculum system of humanistic quality education and adhere to the combination between inside and outside of the class, between inside school and outside school. The third is, through the construction of campus culture, to create a rich and healthy campus cultural atmosphere, influence the value mode of thinking and behavior habits, improve their personality, temperament and self-cultivation, and cultivate their humanities.

\subsection{Innovating the Mode of Talents Cultivation}

In order to cope with the large number of demand for innovative engineering talents under the situation of economic globalization, the reform of engineering education must implement the three strategies, namely, "learning by doing", production \& study cooperation and internationalization. It requires introduction and absorption of CDIO idea about international engineering education and strengthens the local research and practice. In education and teaching practice, we should courage to take the initiative to try to sum up in a timely manner, and actively explore the new path of higher engineering education reform, to improve the quality of talents. At the same time, higher engineering education should strengthen ties and cooperation between the industry and the government. It should establish and implement the professional talent training mode such as " $2+1$ ", " $3+1$ " and " $4+1$ " to enhance the students' participation in the practice experience and the ability to realize seamless docking, training and enterprise demand for talents, cultivate a large number of suitable talents for enterprises. It should innovate training mode of engineering talents, establish the training system engineering master of "oriented by school, based on the project and regarded enterprises as the main body", make full use of the enterprise technological innovation, product development and high level innovative engineering and technical talents to enhance scientific and technological content and market competitiveness of the enterprise products, increase 
the function and value of higher engineering education in talents training to provide powerful support for the construction of new industrialization with Chinese characteristics [5].

\subsection{Improving the Engineering and Practice Ability of Teachers}

The teachers are the first resources and in the leading position in higher engineering education. At present, majority of our teachers who take participate in higher engineering education own a higher degree, but they are generally lack of engineering background and experience and knowledge structure is relatively single. This is a deadly problem.

Therefore, how to improve the staff in higher engineering education as soon as possible is the primary problem. The first is to change the teachers' thought- "only diploma and degree". We should pay attention to the teachers' diploma and at the same time pay more attention to teacher's engineering background and experience. The second is to establish the teacher management system which encourages flexible management to expand the source channel of teachers and optimize the structure of teachers.

The third is to establish the system of teacher training and carry out targeted training practice regularly. The fourth is to actively encourage and support teachers to take participate in exchange program and timely understand the development of engineering education and social demand. The fifth is to establish teachers' practical experience sharing platform and broaden the perspective of teachers to strengthen the practice consciousness and practice experience. The sixth is to strengthen the teachers' teaching research and teaching ability to improve their teaching content organization, guidance and practice experience. The seventh is to implement the appointment system of professional teachers to ensure that the teachers have engineering background and practical experience.

\section{References}

[1] Zhu, H., Li, Z.Y. and Liu, Z.J. (2013) Research and Practice on Higher Engineering Education Reform and Outstanding Engineers Cultivation. Research in Higher Education of Engineering, 11, 68-71.

[2] Zhang, X.H., Wang, W. and Xu, J.P. (2012) Countermeasures for Higher Engineering Education Reform in the New Era. Research in Higher Education of Engineering, 3, 53-56.

[3] Zeng, L.J., Du, M. and Ma, Y.K. (2013) The Exploration of Engineering Education Reform under the Background of the Idea of Large-Scale Engineering. Education Exploration, 9, 35-36.

[4] Li, Z.Y. (2012) Some Thoughts on China’s Higher Engineering Education. China Higher Education, 20, 30-34.

[5] Yin, D.Y. and Cao, G.S. (2013) Practical Teaching Reform and Practice Based on Construction of Modern Engineering Education System. Experimental Technology and Management, 10, 11-14. 